\title{
Bitter Melon (Momordica Charantia) Reduces Serum Sialic Acid in Type2 Diabetics: Evidence to Delay the Process of Atherosclerosis
}

\author{
Inayat Ur Rahman ${ }^{1 *}$, Mohammad Bashir ${ }^{2}$, Mohammad Salman ${ }^{2}$, Mohammad Idrees ${ }^{3}$, \\ Mohammad Iqbal Khan ${ }^{4}$ \\ ${ }^{1}$ Gandhara College of Pharmacy, Gandhara University, Peshawar, Pakistan \\ ${ }^{2}$ Institute of Medical Science, Kohat University of Science \& Technology, Kohat, Pakistan \\ ${ }^{3}$ Department of Pathology, Khyber Medical College, Peshawar, Pakistan \\ ${ }^{4}$ Department of Chemistry, Kohat University of Science \& Technology, Kohat, Pakistan \\ E-mail: "marwax07@yahoo.com,mbashir@yahoo.com,dr_idrees@yahoo.com \\ Received February 7, 2011; revised April 3, 2011; accepted November 17, 2011
}

\begin{abstract}
More than 1000 herbal products have been used by diverse cultures of the world to treat hyperglycemia and among them bitter melon (Momordica charantia) is one of the most popular herbal resource. The beneficial effects of bitter melon is not limited to hypoglycaemia only, but it also ameliorates diet induced obesity, insulin resistance and exhibit cardioprotective effects. The present study attempts to investigate the effect of bitter melon fruit juice on a newly investigated risk factor, sialic acid in type 2 diabetics. A total of 40 type 2 diabetic patients, divided into group $A(n=20)$ and group $B(n=20)$ were investigated during the present study. The patients of group A were following bitter melon fruit juice treatment along with diet control, whereas the patients of group B were on diet control only. Serum sialic acid (SSA) decreased in group A from $66.20 \pm 2.30 \mathrm{mg} / \mathrm{dl}$ to $63.50 \pm 2.10 \mathrm{mg} / \mathrm{dl}(<0.11)$ but, increased in group B from $66.50 \pm 1.70 \mathrm{mg} / \mathrm{dl}$ to $68.20 \pm 2.50 \mathrm{mg} / \mathrm{dl}(<0.12)$, compared to baseline. Post-treatment between group comparison revealed a significant difference $(<0.05)$. The beneficial effects on fasting plasma glucose (FPG) and glycohemoglobin (HbA1-c) were also greater in group A compared to group B as was the case with blood lipids, weight and blood pressure. The study provides another mechanism for the cardioprotective effect of bitter melon and further strengthens its value in the management of type 2 diabetes.
\end{abstract}

Keywords: Sialic Acid, Type2 Diabetes Mellitus, Bitter Melon, Cardiovascular Disease

\section{Introduction}

Plant medicines have a long history of use in various pathological conditions. Bitter melon (Momordica charantia) is traditionally used for treating diabetes in developing world including India and Pakistan, which have a long history of the use of herbal remedies in diabetes [1]. Bitter melon is a traditional plant used by ayurvedic doctors of medicines to benefit various conditions including diabetes [2]. The effect of bitter melon on various diabetes associated cardiovascular risk factors like plasma lipids, obesity and insulin resistance is known $[3,4]$ and the present study is designed to determine the effect of bitter melon on a recently investigated cardiovascular (CV) risk marker/factor, sialic acid. Sialic acid is used to be a group name for acetylated derivatives of neuraminic acid and the serum level of it is increased in type 2 diabetes mellitus [5-8]. The mechanistic aspect of raised levels of serum sialic acid (SSA) is not very clear, but several possibilities have been suggested for elevated levels in diabetic patients. There may be generalized endothelial cell dysfunction or macrovascular disease, either through loss of sialic acid containing glycoproteins from vascular cells into blood stream or through an acute phase response. Circulating sialic acid is mostly covalently attached to glycoproteins, particularly the acute phase group. Type2 diabetes mellitus may be considered an acute phase disease, since in type 2 diabetes (not type 1 diabetes), even without tissue complications, the serum levels of acute phase proteins, C-reactive protein and ha- 
ptoglobin are elevated [9-13].

There may be increased sialylation of serum proteins [14] or reduction in desialylation of plasma glycoproteins [15]. Alternatively or in addition, declining renal function in diabetes may retard the excretion of acute phase proteins or other sialic acid containing proteins, leading to high SSA levels [16]. Recent studies indicate a positive association between SSA and cardiovascular mortality and has been proposed to be a long term predictor of coronary artery disease in adults, particularly women [17].

The evidence of raised level of SSA as a risk factor for cardiovascular disease (CVD) signifies the importance of its status in diabetes mellitus. Therefore, the present study was carried out to test our hypothesis that bitter melon induced reduction in blood glucose and blood lipids are associated with changes (reduction) in SSA in type2 diabetics.

\section{Materials and Methods}

\subsection{Study Design}

A total of 40 recently diagnosed type 2 diabetic patients attending Afghan Dawakhana, Lakki Marwat, were investigated during the present study. They were divided into two groups, A and B. The patients in group A (20) were on diet control only, whereas, the patients in group B (20) were also taking freeze-dried bitter melon juice in a dose of $1 \mathrm{~g} / \mathrm{d}$ along with diet control. The volunteer patients of type 2 diabetes were explained the research protocol and their written informed consents obtained for the study. Participants were informed of their right to withdraw from the study at any time. The study was conducted for a period of 12 weeks. Therapeutic goal was to achieve FPG level $<140 \mathrm{mg} / \mathrm{dl}$, while observing the changes in SSA.

\subsection{Procedures and Measurements}

Fasting blood samples were collected after $12-14 \mathrm{~h}$ overnight fast without the use of a tourniquet. Metabolic variables were determined at baseline and at the end of the study period.

Sialic acid was determined by using a method proposed by Shamberger [18]. In brief, sialic acid in the sample reacts with Ehrlich's reagent and this result in the formation of a white precipitate. After incubation in water bath the colour of the mixture turned blue from white. Sodium chloride was added to the mixture and centrifuged. The intensity of the colour of supernatant is directly proportional to the concentration of sialic acid and is read in a spectrophotometer at $525 \mathrm{~nm}$.

Fasting plasma glucose (FPG), glycohemoglobin (HbA1-c), total cholesterol (TC), high density lipoprotein cholesterol (HDL-c), low density lipoprotein cholesterol (LDL-c) and triglyceride (TG) levels were analyzed by enzymatic methods, using commercially available kits.

SSA, HbA1-c and blood lipids were determined at start and at the end of the study period whereas FPG was determined at start and then after every 2 weeks.

Standing height and weight were measured with the subjects in light clothing and without shoes. Height was recorded to the nearest centimetre and weight to the nearest $0.1 \mathrm{Kg}$. The weighing scales (Detecto-Medic, NY, USA) were standardized on each visit using standard weights of 20 and $70 \mathrm{Kg}$. Body mass index (BMI), defined as weight in $\mathrm{Kg} /$ height (in meters) squared was calculated, and used as an index for obesity. Obesity was defined according to the WHO standards as BMI $<30$ [19]. Blood pressure was measured according to a standard protocol [20]. Hypertension was defined as systolic blood pressure $160 \mathrm{mmHg}$ and/or diastolic blood pressure $95 \mathrm{mmHg}$ and/or current history of antihypertensive medications, according to the WHO criteria [21].

\subsection{Source and Preparation of Bitter Melon Fruit Juice}

Momordica charantia (family Cucurbitaceae, commonly known as $\mathrm{Ku}$ gua, bitter melon, karela or bitter gourd) was purchased from a local market in Khyber Pukhtoonkhwa Province, Pakistan and authenticated by a pharmacognosy expert before juice preparation. The juice was prepared by the method proposed by Chen et al. [22]. Unripe bitter melon fresh fruit was washed thoroughly with water, cut open and the seeds removed. The juice was extracted from the edible portion by crushing the fruit in electric juicer (NOVA-Osaka, Japan) and straining through a muslin cloth. The yield was $390 \mathrm{ml} / \mathrm{Kg}$. The juice was frozen and then completely lyophilized by continuous freeze drying operation for $72 \mathrm{~h}$ (Dura Bulk Tray Dryer, FTS System, Stone Ridge, NY). The yield was $7 \mathrm{~g}$ powder $/ \mathrm{Kg}$ of fresh fruit. The powder was filled in hard gelatine capsules in a dose of $0.5 \mathrm{~g}$ and $1 \mathrm{~g}$.

Results are expressed as means $\pm \mathrm{SD}$. Data were analysed using the Statistical Package for Social Sciences, SPSS (SPSS Inc., Chicago, IL, USA) and a P $\leq 05$ was taken as the cut-off level for significance. Because the distribution of most variables was not symmetric, we used non-parametric statistical methods. The Mann-Whitney U-test was used for between group comparisons and Kruskal-Wallis one-way ANNOVA test was used for comparisons involving more than two groups.

\section{Results}

Table 1 shows baseline characteristics of the study groups. 
There were no significant differences of metabolic variables among the groups. Table 2 shows the post-treatment values of metabolic variables. Serum sialic acid (SSA) showed a trend towards decrease in group A from $66.20 \pm 2.30 \mathrm{mg} / \mathrm{dl}$ to $63.50 \pm 2.10 \mathrm{mg} / \mathrm{dl}(<0.11)$ whereas, increased in group B from $66.50 \pm 1.70 \mathrm{mg} / \mathrm{dl}$ to $68.20 \pm 2.50 \mathrm{mg} / \mathrm{dl}(<0.12)$. Post-treatment between group comparisons revealed a significantly high SSA in group B (Figure 1).

Fasting plasma glucose (FPG) decreased to $<140$ $\mathrm{mg} / \mathrm{dl}$ within the first month of study in both group A and group B. After that, the level deteriorated $(\geq 140$ $\mathrm{mg} / \mathrm{dl}$ ) more rapidly in group B than group A (Figure 2). HbA1-c significantly decreased in both group A and group B, compared with baseline (Table 2).

Table 1. Baseline characteristics of group A and group B.

\begin{tabular}{ccc}
\hline Variable & Group A & Group B \\
\hline $\mathrm{N}$ & 20 & 20 \\
Age (y) & $52 \pm 3.40$ & $52.20 \pm 4.70$ \\
Sex (M/F) & $8 / 12$ & $9 / 11$ \\
BMI (Kg/m $)$ & $26 \pm 2.20$ & $26.70 \pm 2.80$ \\
Weight (Kg) & $77.60 \pm 4.30$ & $77 \pm 4.40$ \\
SBP (mmHg) & $139 \pm 6$ & $138 \pm 5$ \\
DBP (mmHg) & $94 \pm 3$ & $95 \pm 3$ \\
Smoking (cig/d) & 8 & 10 \\
SSA (mg/dl) & $66.20 \pm 2.30$ & $66.50 \pm 1.70$ \\
FPG (mg/dl) & $151 \pm 6.20$ & $148 \pm 6.80$ \\
HbA1-c (\%) & $8.60 \pm 0.40$ & $8.70 \pm 0.50$ \\
TC (mg/dl) & $196.30 \pm 6.10$ & $194 \pm 5.60$ \\
HDL-c (mg/dl) & $49.20 \pm 2.90$ & $48.40 \pm 1.50$ \\
LDL-c (mg/dl) & $150.20 \pm 4.20$ & $151.30 \pm 3.50$ \\
TG (mg/dl) & $172.90 \pm 5.10$ & $172.40 \pm 3.60$ \\
\hline
\end{tabular}

Data are mean \pm SD; SBP: Systolic Blood Pressure; DBP: Diastolic Blood Pressure; SSA: Serum Sialic Acid; FPG: Fasting Plasma Glucose; HbA1-c: Glycohemoglobin; TC: Total Cholesterol; HDL-c: High Density Lipoprotein cholesterol; LDL-c: Low Density Lipoprotein cholesterol; TG: Triglyceride.

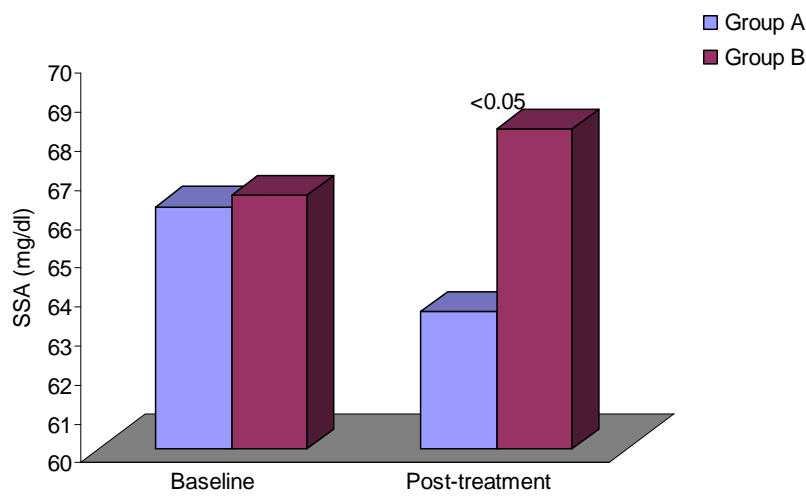

Figure 1. Comparison of baseline and post-treatment SSA in group $A$ and group $B$.

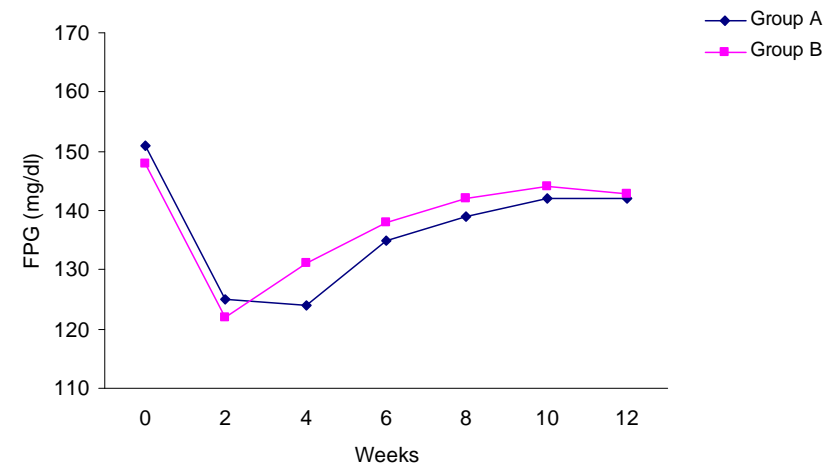

Figure 2. Changes in FPG overtime.

Table 2. Post-treatment biochemical profile of group $A$ and group B.

\begin{tabular}{|c|c|c|c|c|}
\hline \multicolumn{3}{|c|}{ Group A } & \multicolumn{2}{|c|}{ Group B } \\
\hline Variable & $\begin{array}{c}\text { Post-treatment } \\
\text { value }\end{array}$ & $\begin{array}{c}\text { Change } \\
\text { from } \\
\text { baseline } \\
\text { P-value }\end{array}$ & $\begin{array}{c}\text { Post-treatment } \\
\text { value }\end{array}$ & $\begin{array}{c}\text { Change } \\
\text { from } \\
\text { baseline } \\
\text { P-value }\end{array}$ \\
\hline SSA (mg/dl) & $63.50 \pm 2.10$ & $<0.11$ & $68.20 \pm 2.50$ & $<0.12$ \\
\hline FPG (mg/dl) & $142 \pm 3.10$ & $<0.05$ & $142.70 \pm 5.60$ & $\leq 0.05$ \\
\hline HbA1-c (\%) & $7.50 \pm 0.30$ & $<0.01$ & $7.50 \pm 0.60$ & $<0.02$ \\
\hline $\mathrm{TC}(\mathrm{mg} / \mathrm{dl})$ & $187.30 \pm 5.90$ & $<0.05$ & $198.30 \pm 8.70$ & $<0.07$ \\
\hline $\begin{array}{l}\text { HDL-c } \\
(\mathrm{mg} / \mathrm{dl})\end{array}$ & $53 \pm 5.30$ & $<0.12$ & $51.30 \pm 4.50$ & $<0.18$ \\
\hline $\begin{array}{l}\text { LDL-c } \\
(\mathrm{mg} / \mathrm{dl})\end{array}$ & $144.10 \pm 5.20$ & $<0.05$ & $154.70 \pm 7.10$ & $<0.12$ \\
\hline $\mathrm{TG}(\mathrm{mg} / \mathrm{dl})$ & $170.50 \pm 8.80$ & $<0.24$ & $171.40 \pm 7.50$ & $<0.20$ \\
\hline Weight (Kg) & $75.50 \pm 4.50$ & $<0.13$ & $77.90 \pm 4.30$ & $<0.19$ \\
\hline $\begin{array}{c}\mathrm{SBP} \\
(\mathrm{mmHg})\end{array}$ & $137 \pm 5.10$ & $<0.19$ & $139 \pm 6.70$ & $<0.20$ \\
\hline $\begin{array}{c}\text { DBP } \\
(\mathrm{mmHg})\end{array}$ & $92 \pm 6.70$ & $<0.22$ & $97 \pm 4.10$ & $<0.21$ \\
\hline
\end{tabular}

Changes occurred in blood lipids during the study period are given in Table 2. Total cholesterol (TC) changed by $-9 \mathrm{mg} / \mathrm{dl}$ and $+4.30 \mathrm{mg} / \mathrm{dl}$ in group A and group B respectively. High density lipoprotein cholesterol (HDL-c) changed by $+3.80 \mathrm{mg} / \mathrm{dl}$ and $+2.90 \mathrm{mg} / \mathrm{dl}$. Low density lipoprotein cholesterol (LDL-c) changed by $-6.10 \mathrm{mg} / \mathrm{dl}$ and $+3.40 \mathrm{mg} / \mathrm{dl}$. Triglyceride (TG) changed by -2.40 $\mathrm{mg} / \mathrm{dl}$ and $-1 \mathrm{mg} / \mathrm{dl}$ in group A and group B respectively.

Weight $(\mathrm{Kg})$ decreased by -2.10 in group $\mathrm{A}$ and increased by +0.90 in group B. Both systolic and diastolic blood pressure (SBP and DBP) decreased in group A by $-2 \mathrm{mmHg}$ each, whereas increased by $+1 \mathrm{mmHg}$ and +2 $\mathrm{mmHg}$ in group B respectively (Table 2 ).

\section{Discussion}

Diabetes is the metabolic syndrome associated with both 
microvascular and macrovascular complications and among these cardiovascular complications is the main cause of death in such patients [22]. Therefore modulation of the cardiovascular risk factors will definitely prove helpful to reduce the incidence of cardiovascular complications in these patients. Results of the present study suggest that the use of bitter melon in type2 diabetes decreases the SSA level thereby indicating the usefulness of bitter melon in protecting against $\mathrm{CV}$ complications in diabetes. Lindberg et al. [23] have shown that the predicting power of sialic acid for coronary heart disease is more or of the same magnitude to that of cholesterol. Recent studies also indicate sialic acid as an independent risk factor for cardiovascular disease [24] and thus any positive change (decrease) in SSA may lead to control and deceleration of atherosclerotic process. Indeed, a significant decrease in SSA levels in growth hormone deficient patients after receiving growth hormone therapy has been related to the prognostic effect of this hormone in groups at risk of cardiovascular disease [25].

There may be several reasons for beneficial effects of bitter melon on SSA including, the inhibitory effect on glycation of LDL-c [26], protecting the biological systems from potentially harmful effects of free radicals due to antioxidant properties [27,28], reduces adiposity and exerts antihyperlipidemic effects [29,30]. A positive association between SSA, blood lipids and BMI have been reported [31]. The role of bitter melon in protecting against cardiovascular complications of diabetes has been reported previously $[32,33]$ and a decrease in SSA shown in this study is the novel finding because it is an indicative of a decrease in the development and progression of atherosclerosis.

\section{References}

[1] J. H. McNeill, "Experimental Models of Diabetes," 1st Edition, CRC Press, Boca Raton, 1999.

[2] E. Basch, S. Gabardi and C. Ulbricht, "Bitter Melon (Momordica Charantia): A Review of Efficacy and Safety," American Journal of Health-System Pharmacy, Vol. 60, No. 4, 2003, pp. 356-359.

[3] J. K. Grover and S. P. Yadav, "Pharmacological Actions and Potential Uses of Momordica Charantia, a Review," Journal of Ethnopharmacology, Vol. 93, No. 1, 2004, pp. 123-132. doi:10.1016/j.jep.2004.03.035

[4] P. Chaturvedi, "Role of Momordica Charantia in Maintaining the Normal Levels of Lipids and Glucose in Diabetic Rats Fed a High-Fat and Low-Carbohydrate Diet," British Journal of Biomedical Science, Vol. 62, No. 3, 2005, pp. 124-126.

[5] J. C. Pickup, M. B. Mattock, M. A. Crook, et al., "Serum Sialic Acid Concentration and Coronary Heart Disease in NIDDM," Diabetes Care, Vol. 18, No. 8, 1995, pp.
1100-1103. doi:10.2337/diacare.18.8.1100

[6] J. C. Pickup, G. A. Roberts, A. M. Kehley, et al., "Higher Serum Sialic Acid in Women than in Men with NIDDM: Possible Relevance to Cardiovascular Risk in NIDDM Women," Diabetes Care, Vol. 20, 1997, p. 1494.

[7] V. Vijay, C. Snehalatha, A. Ramachandran and M. Jayaraman, "Serum Sialic Acid in South Indian Type2 Diabetic Patients with Microvascular Complications," Diabetic Medicine, Vol. 15, No. 2, 1998, p. 176. doi:10.1002/(SICI)1096-9136(199802)15:2<176::AID-DI A553>3.0.CO;2-A

[8] N. Abdella, A. O. Akanji, O. A. Mojiminiyi, et al., "Relation of Serum Total Sialic Acid Concentrations with Diabetic Complications and Cardiovascular Risk Factors in Kuwaiti Type2 Diabetic Patients," Diabetes Research and Clinical Practice, Vol. 50, No. 1, 2000, pp. 65-72. doi:10.1016/S0168-8227(00)00144-3

[9] M. Crook, P. Tutt, H. Simpson and J. C. Pickup, "Serum Sialic Acid and Acute Phase Proteins in Type1 and Type2 Diabetes Mellitus," Clinica Chemica Acta, Vol. 219, No. 1-2, 1993, pp. 131-138. doi:10.1016/0009-8981(93)90204-H

[10] K. Taniuchi, K. Chifu, N. Hayashi, et al., "A New Enzymatic Method for the Determination of Sialic Acid and Its Application as a Marker of Acute Phase Reactants," Kobe Journal of Medical Sciences, Vol. 27, 1981, pp. 91-102.

[11] D. Thompson, S. P. Hrrison, S. W. Evans and J. T. Whicher, "Insulin Modulation of Acute Phase Protein Production in a Human Hepatoma Cell Line," Cytokine, Vol. 3, No. 6, 1991, pp. 619-626. doi:10.1016/1043-4666(91)90489-Z

[12] M. Haq, S. Haq, P. Tutt and M. Crook, "Serum Total Sialic Acid and Lipid Associated Sialic Acid in Normal Individuals and Patients with Myocardial Infarction and Their Relationship to Acute Phase Proteins," Annals of Clinical Biochemistry, Vol. 30, 1993, pp. 383-386.

[13] S. P. Campos and H. Baumann, "Insulin Is a Prominent Modulator of the Cytokine Stimulated Expression of Acute Phase Plasma Proteins," Molecular and Cellular Biology, Vol. 12, 1992, pp. 1789-1797.

[14] M. D. Flynn, R. J. M. Corrall, P. J. Waters and C. A. Pennock, "Sialic Acid and Cardiovascular Mortality," British Medical Journal, Vol. 302, 1991, pp. 533-534. doi:10.1136/bmj.302.6775.533-c

[15] A. G. Morell, G. Gregoriadis, I. H. Scheinberg, et al., "The Role of Glycoproteins in the Circulation," The Journal of Biological Chemistry, Vol. 246, 1971, pp. 1461-1467.

[16] M. A. Crook, K. Earle, A. Morocutti, et al., "Serum Sialic Acid, a Risk Factor for Cardiovascular Disease, Is Increased in IDDM Patients with Microalbuminuria and Clinical Proteinuria," Diabetes Care, Vol. 17, No. 4, 1994, pp. 305-309. doi:10.2337/diacare.17.4.305

[17] A. Vaya, C. Falco, E. Reganon, et al., "Influence of Plasma and Erythrocyte Factors on Red Blood Cell Aggregation in Survivors of Acute Myocardial Infarction," Thromb Haemostas, Vol. 91, 2004, pp. 354-359. 
[18] R. J. Shamberger, "Serum Sialic Acid in Normal and Cancer Patients," Journal of Clinical Chemistry \& Clinical Biochemistry, Vol. 22, 1984, pp. 64-67.

[19] World Health Organization, "Diet, Nutrition and the Prevention of Chronic Diseases," Report of a WHO Study Group, Technical Report Series 1990, No. 797, World Health Organization, Geneva, 1990.

[20] J. D. Cohen, R. H. Grimm and W. M. Smith, "The Multiple Risk Factor Intervention Trial (MRFIT) 4: Intervention on Blood Pressure," Preventive Medicine, Vol. 10, No. 4, 1981, pp. 501-518. doi:10.1016/0091-7435(81)90062-1

[21] World Health Organization Expert Committee, "Arterial Hypertension," Technical Report Series, No. 628, WHO, Geneva, 1978.

[22] A. D. Paterson, B. N. Rutledge, P. A. Cleary, et al., "The Effect of Intensive Diabetes Treatment on Resting Heart Rate in Type1 Diabetes: The Diabetes Control and Complications Trial (DCCT), Epidemiology of Diabetes Interventions and Complications Study," Diabetes Care, Vol. 30, No. 8, 2007, pp. 2107-2112. doi: $10.2337 / \mathrm{dc} 06-1441$

[23] G. Lindberg, L. Rastam, B. O. Gullber and G. A. Eklund, "Serum Sialic Acid Concentration Predicts Coronary Heart Disease and Stroke Mortality: Multivariate Analysis Including 54385 Men and Women during 30.5 Years Follow-up," International Journal of Epidemiology, Vol. 21, No. 2, 1992, pp. 253-257. doi:10.1093/ije/21.2.253

[24] M. W. Knuiman, G. F. Watts and M. L. Divitini, "Is Sialic Acid an Independent Risk Factor for Cardiovascular Disease: A 17 Year Follow-up Study in Busselton, Western Australia," Annals of Epidemiology, Vol. 14, No. 9, 2004, pp. 627-632. doi:10.1016/j.annepidem.2003.09.017

[25] M. Pfeifer, R. Verhovee, B. Zizek, et al., "Growth Hormone Reverses Early Atherosclerotic Changes in Growth Hormone Deficient Adults," The Journal of Clinical Endocrinology \& Metabolism, Vol. 84, No. 2, 1999, pp. 453-457. doi:10.1210/jc.84.2.453

[26] C. L. Hsieh, Y. C. Lin, W. S. Ko, et al., "Inhibitory Effect of Some Selected Nutraceutic Herbs on LDL Glycation
Induced by Glucose and Glyoxal," Journal of Ethnopharmacology, Vol. 102, No. 3, 2005, pp. 357-363. doi:10.1016/j.jep.2005.06.044

[27] N. M. Ansari, L. Houlihan, B. Hussain and A. Pieroni, "Antioxidant Activity of Five Vegetables Traditionally Consumed by South-Asian Migrants in Bradford, Yorkshire, UK," Phytotherapy Research, Vol. 19, No. 10, 2005, pp. 907-911. doi:10.1002/ptr.1756

[28] D. M. Lee, W. H. Hoffman, G. F. Carl, et al., "Lipid Peroxidation and Antioxidant Vitamins Prior to, during, and after Correction of Diabetic Ketoacidosis," Journal of Diabetes and Its Complications, Vol. 16, No. 4, 2002, pp. 294-300. doi:10.1016/S1056-8727(01)00215-X

[29] L. L. Chan, Q. Chen, A. G. G. Go, E. K. Y. Lam and E. S. T. Li, "Reduced Adiposity in Bitter Melon (Momordica Charantia)-Fed Rats Is Associated with Increased Lipid Oxidative Enzyme Activities and Uncoupling Protein Expression," Biochemical and Molecular Actions of $\mathrm{Nu}$ trients, Vol. 135, No. 11, 2005, pp. 2517- 2523.

[30] I. Ahmad, M. S. Lakhani, M. Gillett, et al., "Hypotriglyceridemic and Hypocholesterolemic Effects of Antidiabetic Momordica Charantia (Karela) Fruit Extract in Streptozotocin Induced Diabetic Rats," Diabetes Research and Clinical Practice, Vol. 51, No. 3, 2001, pp. 155-161. doi:10.1016/S0168-8227(00)00224-2

[31] M. Crook, P. Lumb, V. Andrews and R. Swaminathan, "Serum Total Sialic Acid, a Reputed Cardiovascular Risk Factor, and Its Relationship to Lipids, Plasma Fasting Insulin, Blood Pressure and Body Mass Index in Normal Individuals,” Clinical Science, Vol. 95, 1998, pp. 53-57. doi:10.1042/CS19970239

[32] S. S. Dhanasekar and S. Subramanian, "Antioxidant Properties of Momordica Charantia (Bitter Gourd) Seeds on Streptozotocin Induced Diabetic Rats," Asia Pacific Journal of Clinical Nutrition, Vol. 14, No. 2, 2005, pp. 153-158.

[33] R. Gebhardt, "Antioxidative, Antiproliferative and Biochemical Effects in HepG2 Cells of a Homeopathic Remedy and Its Constituent Plant Tinctures Tested Separately or in Combination," Arzneimittelforschung, Vol. 53, No. 12, 2005, pp. 823-830. 